DOI 10.37882/2500-3682.2020.10.01

\title{
ПОНЯТИЕ МОТИВАЦИОННО-ПОТРЕБНОСТНАЯ СФЕРА ЛИЧНОСТИ В ПСИХОЛОГИЧЕСКИХ ИССЛЕДОВАНИЯХ
}

\section{THE CONCEPT OF MOTIVATIONAL- NEED SPHERE OF PERSONALITY IN PSYCHOLOGICAL RESEARCH}

\section{E. Bartul \\ K. Pisarevsky}

Summary: The article reviews the main research on the topic of motivational-need sphere of a person. In the historical perspective, the existing theories of motivation of foreign and Russian researchers are considered. The characteristic of such concepts as motive, motivation and motivational sphere of personality is given. The emphasis is placed on the need for further research of the motivational - need sphere of the individual in the changing value system of modern society.

Keywords: motive, motivation, personality motivation, needs, human behavior.
Бартуль Екатерина Сергеевна

Аспирант, Дальневосточный федеральный университет, г. Владивосток bartul.k@mail.ru

Писаревский Константин Леонидович старший преподаватель, ФГБОУ ВО «Московский государственный университет технологий и управления им. К.Г. Разумовского (ПКУ)», г. Москва, starway48@yandex.ru

Аннотация: В статье сделан обзор основных исследований на тему мотивационно - потребностной сферы человека. В исторической перспективе рассмотрены существующие теории мотивации зарубежных и российских исследователей. Дается характеристика таких понятий как мотив, мотивация и мотивационная сфера личности. Сделан акцент на необходимости дальнейшего исследования мотивационно-потребностей сферы личности в условиях изменяющейся системы ценностей современного общества.

Ключевые слова: мотив, мотивация, мотивация личности, потребности, поведение человека.

и разработано достаточное количество теорий, исследование мотивационно-потребностной сферы до сих пор является одной из актуальных проблем в современной психологии мотивации. Актуальность темы обуславливается динамично развивающиеся и меняющиеся условия жизни и развития человека, что приводит к возникновению новых стимулов поведения и потере ценности старых, неактуальных.

Важно также отметить, что развитие сознания человека тесным образом связано с его потребностями. Представители психологических концепций и ряда других наук, которые исследуют природу человека, признают ведущую роль потребностей в жизни людей, считая их основным источником, который дает энергию для эффективной и продуктивной жизнедеятельности. «Потребности представляют собой основной источник жизненной активности личности, основное ее проявление и важнейший дифференцирующий момент в характеристике личности», - пишет известный отечественный психофизиолог В.Н. Мясищев [3].

В трудах отечественных и зарубежных психологов существуют множество теорий, рассматривающих мотивационную сферу человека. Если обратиться к истории вопроса, то к числу первых психологических теорий можно отнести концепции западных психологов, которые занимались изучением природы личности человека. Например, психоаналитическая концепция, основателем которой был Зигмунд Фрейд рассматрива- 
ла бессознательное личности, включающее в себя природные инстинкты либидо и мартидо, как основополагающий мотивационный фактор, который в дальнейшем предопределяют поведение человека. 3. Фрейд, будучи сторонником биологизаторских теорий мало уделял вниманию социальному, обозначая его как среду, внутри которой происходит реализация биологически-обусловленной направленности личности. Даже потребность в творчестве по своей природе автор относит к защитному механизму сублимации психологических инстинктов, который мотивировал человека на создание нового. Таким образом, с точки зрения Фрейда основные потребности человека сводятся к удовлетворению базовых инстинктов, и свобода выбора поведения сводится практически к минимуму.

Последователи 3. Фрейда рассматривали природу потребностей человека шире. Например К. Юнг, исследуя природу личности вводит такие понятия как «самость», «интроверсия», «экстраверсия и «архетипы», обозначая в них мощную мотивационную энергию, которая направляет человека не только на удовлетворение своих базовых потребностей, но и к творческой, духовной реализации. Юнг, в контексте своей теории указывал на то, что творческое начало заложено в человеческой природе, и основная задача человека заключается в том, чтобы встретиться со своей самостью, то есть раскрыть личностный потенциал во всей его полноте и единстве личности.

Представители гуманистического направления, такие как К. Роджерс, А. Маслоу также рассматривали в качестве побудительных мотивов выбора и деятельности личности потенциал, заложенный природой в самом человеке. К. Роджерс изучал природу человека целостно. Внешняя среда, по его утверждению, может обеспечить только условия для раскрытия личностного потенциала, но, сформировать его она не сможет. Он говорил о том, что доверившись «внутреннему Я» и создав благоприятные внешние условия, будет происходить конгруэнтный процесс развития и саморазвития личности человека.

В это же время представители поведенческих и когнитивных подходов (Д. Уотсон, Б. Скиннер, У. Найсер) рассматривали мотивационные процессы через призму поведенческих навыков с одной стороны и когнитивных установок с другой, не объединяя в своих теориях эти явления. В поведенческих теориях мотивация состояла из комплекса простых и сложных реакций (речь идет о схеме «стимул - реакция - подкрепление»), формируемых в процессе социализации человека. В когнитивном подходе описываются побудительные процессы через когнитивные установки (конструкты), предусматривающие процессы прогнозирования, оценки, приписывания, интерпретации, ожидания и другие, определяющие ведущую роль сознания в детерминации поведения че- ловека.

Вопрос о мотивации, является наиболее первостепенным в концепции А. Маслоу. Он полагал, что личность человека мотивирована на поиск и удовлетворение личных целей, благодаря чему мотивационные процессы являются краеугольным камнем гуманистической теории личности.

А. Маслоу описывал человека следующими словами: «тот, кто постоянно стремится к удовлетворению своих желаний», и, несмотря на это, нечасто достигает состояния полного и завершенного удовлетворения. Отсутствие желаний и потребностей недолговечно. Если одна из потребностей с точки зрения А. Маслоу удовлетворена, то другая всплывает на поверхность и направляет внимание и усилия человека. После ее удовлетворения появляется следующая потребность. Таким образом, жизнь человека происходит в постоянном удовлетворении потребностей, и это непрерывный процесс. [4].

А. Маслоу пишет: «Человек считает абсолютной, наиглавнейшей ценностью, синонимом самой жизни ту потребность из иерархии потребностей, желание удовлетворить которую доминирует в нём в данное время» [4]. Такие потребности, которые надо удовлетворить «В данное время» служат» ступенями лестницы, ведущей к единой конечной цели».

По А. Маслоу, потребность можно считать основной, если она соответствует одновременно следующим показателям:

1. испытывающий в чём-то потребность индивид постоянно жаждет её удовлетворения;

2. неудовлетворённость потребности приводит к заболеванию индивида;

3. удовлетворение имеет психотерапевтический эффект, излечивая индивида от болезни, вызванной дефицитом удовлетворения потребности;

4. недопущение дефицита предотвращает заболевание;

5. у здоровых (удовлетворённых) людей низшие потребности не проявляются, а проявляются потребности высшего порядка [2].

Таким образом, А. Маслоу разработал концепцию иерархии фундаментальных потребностей, в которой он выдвинул гипотезу, что все потребности человека врожденные, или инстинктоидные, организованы в единую иерархическую систему, где одна потребность имеет приоритет над другой. В соответствии с его теорией человеческие потребности последовательно располагаются от низших (физиологических) потребностей организма (в еде, сне, сексе и др.) до высших. К потребностям низшего уровня он относил биологическую составляющую, отвечающую за выживание человека, в потребно- 
стях среднего уровня, видел социальную составляющую, отвечающую за социальную адаптацию и реализацию. К высшим потребностям он относил те, которые обеспечивают сущностную самореализацию человека. Теория мотиваци А.Маслоу является одной из наиболее тщательно описанных и обоснованных, имеет большое значении для психологии с точки зрения понимания того, что является объединяющим общим для человека. В то же время к этой теории ест вопросы, связанные с индивидуальными особенностями человека, влиянием культурной и психологической среды формирование потребностей.

Одним из авторов теорий мотивации, который нередко упоминается в психологической литературе, является Дэвид Макклелланд, - американский психолог, профессор. Изучая человеческие побуждения, он выделил три группы первостепенных мотивов, которые побуждают человека к действию:

- мотив достижения,

- мотив причастности (партнерства),

- мотив власти.

В основе его теории, лежало утверждение о том, что мотивы не являются чем - то фиксированным и статичным. Они формируются в процессе онтогенеза человека, и по мере его развития приобретают все более сложные и иерархичные структуры.

Также как и А. Маслоу, Д. Макклелланд поддерживал идею о том, что биологические потребности, лежат в нижней части иерархической пирамиды, и составляют базисную основу, обеспечивающую выживание человека. Однако вместе с тем, существуют и другие формы потребностей, которые также обеспечивают не только биологическое выживание, но и социальную реализацию человека, среди себе подобных. Автор полагал, что люди имеют целый комплекс мотивов и они по своему составу являются смешанными, однако он вывел гипотезу о том, что определенная часть людей в своем поведении имеет выраженный однонаправленный вектор мотивации. И бессознательно управляемый этим вектором, человек находит наиболее подходящие формы реализации себя в социальном контексте и своей профессиональной деятельности. На основании этих векторов формируются руководители, сотрудники, исследователи и т.д. [8].

Дальнейшие труды Д. Макклелланда основывались на компетентностной теории личности и дополняла его ранние исследования. Рассматривая наличие определенных качеств «компетенций», он внес огромный вклад в теоретико - методологические исследования, связанные с подбором профессиональных кадров. Говоря о вкладе Макклелланда в теорию изучения потребностей и мотивации личности, важно отметить, что влияние его идей распространились и на другие сферы, включая социологию, экономику, религию и политику. Макклел- ланд считал, что обществу и государству следует формировать человека с правильным типом мотивационной потребности и стремлением реализовать планы, чтобы добиваться успеха [1].

В трудах российских авторов понятие мотивации также рассматривалось различными исследователями. Одним из первых является Иван Петрович Павлов и его теория условно-рефлектороного поведения. Согласно его концепции, основой мотивации животного мира является два вида рефлексов, безусловные и условные. Если первые передаются генетически, переходя из поколения в поколения, то вторые являются частью приобретенного опыта, формирующегося в результате многократного повторения взаимодействия живого организма со внешней средой.

В середине 20 века, понятие мотивации с позиции «теории установки», рассматривал Дмитрий Николаевич Узнадзе. Его позиция отражала идею о том, что основополагающим источником активности и деятельности человека является реализация той потребности организма, которая на данный момент не реализована. Через свою теорию Д.Н. Узнадзе попытался объяснить активность и поведение живого организма в его контакте с внешней реальностью. В основе такого взаимодействия автор видел установку, которая и предопределяет рациональные или иррациональные формы поведения. Установка - это готовность организма или субъекта к совершению определенного действия или реагирования в определенном направлении.

Узнадзе подчеркивает, что установка возникает при соблюдении двух элементарных условий:

- потребность должна быть актуальной в текущий момент времени:

- присутствие ситуации, внутри которой происходит удовлетворение или неудовлетворение данной потребности.

Согласно теории Д.Н. Узнадзе, установка в структуре личности человека является первичным, целостным и недиферинцированным состоянием, которое находится ниже уровня сознания, и является основополагающим фактором, формирующим человеческое поведение. Автор выделяет различные классификации установок, в зависимости от времени возникновения, от особенностей угасания установки, от категории носителя установки [7].

Также среди российских ученых следует выделить А.Н. Леонтьева и его теорию деятельностного происхождения мотивационной сферы личности человека. Согласно его теории, мотивационно-потребностная сфера личности, как и реализация психологических потребностей, имеет свои корни в практической деятельности. Леонтьев отмечает, что между содержанием самой 
деятельности и непосредственно строением мотивационной сферы человека проявляются определенные отношения, изоморфизма, т. е. взаимного согласия, а в основе динамических изменений мотивационной сферы личности, находиться подчиняющееся социальным законам развития система деятельности. Можно смело утверждать, что данная концепция вносит ясность в происхождение и динамику мотивационной сферы человека. Леонтьев раскрывает механизмы, благодаря которым происходит формирование и изменение мотивации, происходит преобразование ее в иерархическую структуру, формируется специфика деятельности и возникновение операций. В соответствии с теорией деятельности, можно вывести ряд законов которые описывают изменение в мотивационной сфере личности, а также особенности формирования новых потребностей, мотивов и целей. Согласно А.Н. Леонтьеву, направленность побуждению придает материальный или нематериальный объект, вместе с чем «опредмечивание потребности», как выражался А.Н. Леонтьев, придает этому побуждению смысл.

Важно подчеркнуть, что мотивом деятельности является не сам предмет, а то субъективное значение, которое человек вкладывает, интерпретируя его значение. Благодаря этому появляется ясность, связанная с рассуждением о «сдвиге мотива на цель», когда стимулирует деятельность уже не желание иметь тот или иной предмет, а выполнение самого действия, получение удовольствия от непосредственного процесса

Исследуя понятие трудовой деятельности, Леонтьев указывает на то, что она общественно мотивирована и, хотя, материальное вознаграждение является немаловажным мотивирующим фактором, смысл непосредственного труда для человека создается «смыслообразующими мотивами», то есть такими мотивами, которые окрашивают непосредственно саму деятельность личностным смыслом. Деньги, являясь побудительным мотивом, только как функция стимулирования, и условно называются «мотивом-стимулом», который не имеет главной функции, которую имеет непосредственно сам труд - функция смыслообразования. [5].

Автор культурно исторической концепции Л.С. Выготский говорил о наличие у человека низших и высших психических функций, благодаря которым и формируются различного рода потребности. Низшие психические функции обеспечивают удовлетворение базовых потребностей, которые присущи не только человеку, но и всему животному миру, в то же время высшие психические функции являются чисто человеческими новообразованиями, и формируются сугубо в социальном контексте. Эти потребности развиваются параллельно и управляют поведением человека на всех уровнях его организации и деятельности, т.е. существует тройственный характер удовлетворения потребностей посредством материального и нематериального стимулирования.

Л.И. Божович выдвигает предположение о том, что материальные предметы, которые постоянно удовлетворяют различного рода потребности, как бы содержат в себе эту потребность. На основании данного суждения они и приобретают способность мотивировать поведение и деятельность человека даже в тех ситуациях, когда соответствующая потребность не была предварительно актуализирована. Таким образом, предметы, в концепции Л.И. Божович, являются лишь мотиваторами потребностей, а не действий или деятельности. Без оживления потребности под воздействием предмета активность человека проявиться не может.

Большой интерес представляет концепция известного отечественного социолога В.А. Ядова, который сформулировал диспозиционную концепцию социального поведения личности. Основная суть теории состоит в том, что личность человека обладает комплексной системой диспозиций (личных предрасположенностей), регулирующих его поведение и деятельность на разных уровнях социальной действительности. С точки зрения Ядова В.А., диспозиции личности представляют собой зафиксированные в социальном опыте предрасположенности, благодаря которым происходит оценка и восприятие окружающей действительности, включающую, собственную активность индивида и действия других. Диспозиции образуются на стыке потребностей, интересов и ситуаций, имеющих сложную структуру [6].

Автор выделяет четыре уровня потребностей, ситуаций и соответствующих им диспозиций:

1. Элементарные фиксированные установки, сформированные на основе витальных потребностей и формирующиеся простейших ситуациях в условиях семейного окружения, и в самых низших «предметных ситуациях»;

2. Более сложные диспозиции, формируемые на основе потребности человека в социальном общении в малой группе. Соответственно, второй уровень составляют социальные фиксированные установки или аттитюды, которые по сравнению с элементарной фиксированной установкой имеют сложную трехкомпонентную структуру (когнитивный, аффективный и поведенческий компоненты);

3. Базовые социальные установки, характеризующие общую направленность интересов личности в определенную сферу труда или досуга;

4. Система ценностных ориентаций, которые регулируют поведение и деятельность личности в наиболее значимых ситуациях ее социальной активности, в каких выражается отношение личности к целям жизнедеятельности, к средствам удовлетворения этих целей, т.е. к обстоятельствам 
жизни личности, детерминированным общими социальными условиями, типом общества, системой его экономических, политических, идеологических и культурных принципов.

Таким образом, в концепции В.А. Ядова рассматривается иерархическая система диспозиционных образований - готовностей личности к действию в определенных условиях и для удовлетворения определенных потребностей. Помимо аттитюдов, в регуляцию поведения и деятельности личности здесь включены и другие диспозиционные образования (первичные установки, базовые социальные установки и ценностные ориентации), действующие на разных уровнях ситуации (или в разных условиях деятельности).

В общей психологии мотивационно - потребностная сфера рассматривается с нескольких ракурсов. Первый, с позиции психологической структуры деятельности, где мотив или система мотивов это то, что побуждает человека к осуществлению деятельности и придает этой деятельности вектор направления, а второй, как отдельная система, выполняющая ряд важных для человека задач и функций. Принято разделать понятие мотива, мотивации и мотивационной сферы личности.

Если говорить о первом, то мотив рассматривается как то, что побуждает человека к деятельности или проявлению себя в определенных жизненных сферах. К мотивам можно отнести мысли, чувства, осознанные или неосознанные желания, связанные с различного рода потребностей. В психологии существует довольно широкое количество взглядов на сущность мотива, как психологического феномена. К ним относятся:

- мотив как то, что побуждает человека к совершению определенного рода действия или ряда действий, для достижения желаемого результата (И.А.Джидарьян, В. Н. Мясищев и др.).

- мотив как то, что удовлетворяет человеческую потребность, в которой содержится активное стремление индивида к изменению окружающей среды с целью удовлетворения своих нужд. (Л.И. Божович, С.Л. Рубинштейн, К.К. Платонов).

- мотив как то, что встроено в систему личности и становиться устойчивой характеристикой человека с такими особенностями как: предпочтения, склонности, установки, ценности, мировоззрение, идеалы (М. Мадсен, Х. Мюррей, Дж. Аткинсон, К. К. Платонов, В.С. Мерлин, М.Ш. Магомед-Эминов и др.).

- мотив как то, что вызывает положительное эмоциональное состояние, приводящее к чувству удовлетворенности, и выступает как один из факторов, влияющих на продолжение деятельности (В.Г. Асеев, А.Г. Ковалев, П.М. Якобсон и др.).
Совокупность внутренних и внешних мотивов, потребности и цели - являются основными составляющими мотивационной сферы человека.

Если говорить о «мотивации», то она является более широким и объемным понятием чем «мотив». В современной психологии этот термин используется в нескольких значениях:

- комплекс факторов (потребности, мотивы, цели, намерения, стремления и многое другое), которые определяют поведение человека и являются достаточно устойчивым базисом личности.

- характеристика непосредственно самого процесса, который запускает и регулирует поведенческую активность личности человека на заданном уровне.

Таким образом, мотивацию можно рассмотреть, как динамический процесс, который происходит на физиологическом и психологическом уровнях, определяющих направленность поведения человека, в результате которого происходит удовлетворение определенного вида потребностей. Мотивация включает в себя комплекс факторов, обладающих побуждающей силой и стимулирующих активность личности к которым относятся мотивы, потребности, стимулы и объясняет целенаправленность действия, организованность и устойчивость целостной деятельности, направленной на достижение определенной цели.

Мотивационная сфера личности - это иерархическая система мотивов личности. Структура мотивационной сферы очень сложная. При этом мотивация выстраивается в определенную иерархию не только внутри каждого вида деятельности, но и происходит ранжирование мотивации различных видов деятельности. Мотивационная сфера, как и другие структурные образования личности, проявляется во множестве качеств. От особенностей преобладающих мотивов зависит, какие именно свойства и качества личности будут формироваться легче, быстрее, а какие - с большими трудностями, медленнее. [5].

К важнейшим характеристикам мотивационной сферы личности относятся:

- множественность (совокупность однородных и разнородных мотивов измеряемых с помощью количественных и качественных показателей);

- структурность (наличие определенных видов мотивов, выстроенных в структуру);

- иерархичность («главенствования» различных групп мотивов в соответствии с определенным порядком соподчиненности, ранжирования);

- сила (показатель непреодолимого стремления личности оценивается по степени и глубине осознания (понимания, «присвоения», «принятия») по- 
требности и мотива, по его интенсивности);

- устойчивость мотивов (проявляется в длительном сохранении действенности мотивации или большинства составляющих мотивов);

- их определенность (мотивационная сфера людей различаются содержанием и структурой мотивации, иерархией, силой и устойчивостью мотивов);

- динамичность (изменении силы, как отдельных мотивов, так и мотивации в целом).

Подводя итоги, следует отметить, что мотивационнопотребностная сфера является одной основополагающих тем, изучаемых в структуре личности человека. Если посмотреть шире, и это то, что отличает представителя вида хомо-сапиенс от всего другого животного мира. Руководствуясь ценностями, мотивами и потребностями, человек выходит пределы своей личности, создавая свою индивидуальность, неповторимость. Он проявляет себя в труде и работе, раскрывая свой творческий потенциал и познавая себя как субъекта деятельности.
Однако, несмотря на весь объем полученных теоретических и эмпирических данных связанных с исследованием мотивационно-потребностной сферы личности, до сих пор остается ряд открытых вопросов, на которые до сих пор нет однозначного ответа. Примером одного из таких вопросов может быть дискуссия по поводу того откуда возникает у человека потребность в духовности, в религии, что его мотивирует на высшие или так называемые высшие чувства такие как (благородство, альтруизм, безусловная любовь, доброта и т.д.). Эти ответы лежат на границе психологических и других отраслей знаний. Более того, важно отметить, что полное исследование мотивационно - потребностной сферы личности не достижимо, по причине того, что меняющие социальные условия жизни индивидов необратимо влекут за собой изменения в мотивационной сфере.

Таким образом, не смотря на весь полученный объем знаний связанный с темой мотивации личности, данная сфера остается той отраслью знаний, которая требует более глубокого и тщательного научного исследования.

1. Макклелланд Д. Мотивация человека. СПб.: 2007. - 672 с.

ЛИТЕРАТУРА

2. Корнеенков С.С. Психология потребностей, их дуальность и гармоничное развитие личности. //Вестник ДВГАЭУ, 1999г., С. 112-120.

3. Мясищев В.Н. Проблемы потребностей В системе психологии. // Ученые записки ЛГу. Психология и педагогика. Л.: 1957. № 244, 2. С. 3-23.

4. Маслоу А. Психология бытия. М.: «Рефл-бук» - К.: «Ваклер», 1997

5. Маклаков А.Г., Общая психология. — СПб.: Питер, 2001. — 592

6. Социальная психология. Теория и практика [Текст]: учебник для бакалавров : учебник для студентов высших учебных заведений, обучающихся по гуманитарным направлениям и специальностям / Н.А. Корягина, Е.В. Михайлова ; Фак. психологии МГУ им. М.В. Ломоносова, Высшая шк. экономики нац. исслед. ун-т. - Москва : Юрайт, 2014.

7. Хекхаузен Х. Мотивация и деятельность. - Спб.: М.: Смысл, 2003 - 860с.

8. Леонтьев А.Н. Потребности. Мотивы. Эмоции // Психология мотивации и эмоций. Хрестоматия / под ред. Ю.Б. Гиппенрейтер, М.В. Фаликман. М.: ЧеРо, 2002. C. 57-65.

9. Горская Н.Е. Теоретические подходы к исследованию структуры мотивации личности. // Вестник Иркутского государственного технического университета. 2015. № 1. C.217-221.

(с Бартуль Екатерина Сергеевна (bartul.k@mail.ru), Писаревский Константин Леонидович (starway48@yandex.ru). Журнал «Современная наука: актуальные проблемы теории и практики» 